\title{
ESTUDO DE MANIFESTACOES PATOLÓGICAS DECORRENTES DA CONSTRUCAO DE FUNDACOES EM SOLO ORGANICO
}

\author{
MARIA ALANYA COSTA OLIVEIRA \\ Estudante \\ UFERSA \\ Rio Grande do Norte; Brasil \\ alanya.oliveira@gmail.com
}

\author{
JOSE HENRIQUE MACIEL DE QUEIROZ \\ Professor \\ UFERSA \\ Rio Grande do Norte; Brasil \\ henrique.jhmq@hotmail.com
}

\author{
RONNIELBE AVELINO MOURA \\ Estudante \\ UFERSA \\ Rio Grande do Norte; Brasil \\ ronnielbeavelino@gmail.com
}

\author{
FILIPE ABRANTES F. CAVALCANTI \\ Estudante \\ UFERSA \\ Rio Grande do Norte; Brasil \\ filipeabrantes_12@hotmail.com
}

\section{RESUMO}

Na construção civil é comum observar problemas relacionados com fundações. A falta de investigação do subsolo afim de conhecer a sua capacidade de carga, tem sido um dos principais fatores para surgimento de problemas. Após o projeto de encerramento dos lixões a céu aberto, pela Política Nacional de Resíduos Sólidos (PNRS), muitos desses locais têm sido invadidos ou até mesmo autorizados por órgãos públicos para ocupação. No entanto, a falta de monitoramento das áreas tem provocado problemas nas obras construídas ali, pois com a modificação das cargas aplicadas no solo e a atuação da água sobre a matéria orgânica recebida durante a vida útil do lixão, surge uma série de patológias nas edificações. Diante disso, o trabalho tem como objetivo discutir, a partir de casos reais, problemas estruturais causados em edificações construídas em terrenos constituídos de solo orgânico. Para alcançar tal objetivo foram realizadas pesquisas bibliográficas de cunho qualitativo. Mediante a pesquisa foi constatado que um dos problemas mais comuns é o recalque diferencial, que é o rebaixamento parcial do solo em detrimento das cargas recebidas. Portanto, é de suma importância que haja sempre uma investigação do subsolo afim de conhecer a capacidade de carga dele antes de construir uma obra, principalmente em terrenos que já tenham recebido grande quantidade de matéria orgânica, como em lixões ou aterros fechados.

Palavras-chave: lixões, recalque, solo.

\section{ABSTRACT}

In civil construction it is common to observe problems related to foundations. The lack of underground investigation in order to know its carrying capacity, has been one of the main factors for the emergence of problems. After the project to close open dumps, under the Política Nacional de Resíduos Sólidos (PNRS), many of these places have been invaded or even authorized by public agencies for occupation. However, the lack of monitoring of the areas has caused problems in the works built there, because with the modification of loads applied to the soil and the action of water on the organic matter received during the life of the dump, a series of pathologies in the buildings appears. Therefore, the work aims to discuss, based on real cases, structural problems caused in buildings built on land consisting of organic soil. To achieve this goal, qualitative bibliographic research was carried out. Through research it was found that one of the most common problems is differential settlement, which is the partial lowering of the soil to the detriment of the incoming loads. Therefore, it is of paramount importance that there is always an investigation of the subsoil in order to know its carrying capacity before building a work, especially in land that has already received a large amount of organic matter, such as in dumps or closed landfills.

Keywords: dumps, repression, soil.

\section{INTRODUCAO}

As fundações na Construção Civil são essenciais no processo de construção de uma edificação. Os elementos de fundação constituem a infraestrutura das construções e fazem parte do subsistema estrutural que compõe qualquer tipo de obra. A depender do tipo de solo e dos tipos de edificação, a fundação empregada pode ser superficial ou profunda. O que 
irá definir esta escolha é a tipologia da obra e as características do terreno de implantação.

Para o conhecimento adequado do solo é necessária uma análise rigorosa. Um dos métodos mais aplicados nessa análise é a sondagem à percussão do terreno, mais conhecido como SPT (ensaio de penetração padrão). O intuito das sondagens à percussão é identificar as camadas do solo em suas profundidades de ocorrência, o nível do lençol freático e sua resistência à cravação de um amostrador padrão. Estas informações, serão fundamentais para que seja definido o tipo de fundação a ser executada posteriormente.

A depender da área de estudo, o solo pode receber distintos conceitos, mas de forma geral, o solo é o conjunto de horizontes ou camadas que se deu pela desintegração da rocha-mãe (Pereira et al, 2004), sofrendo influências físicas e químicas ao longo do tempo pela ação do intemperismo, revelando características peculiares como textura, capacidade estrutural, cor, entre outros fatores. Dentre essas características, este trabalho limitar-se-á a análise do solo orgânico como suporte estrutural.

De acordo com a Pedologia, que é a ciência que estuda os solos, os solos orgânicos são oriundos da decomposição e posterior apodrecimento de matérias orgânicas, sejam estas de natureza vegetal (plantas, raízes) e animal. Para o Marinho (2010), os solos orgânicos são problemáticos para construção por serem muito compressíveis, ou seja, deformável. Neste sentido, estudos tem revelado que, terrenos em que outrora eram lixões e/ou aterros, sofrem alteraçoes no solo ao longo dos anos tornando-se problemas para edificações, como afirma Koswoski (2015) e Aquino (2018).

Conforme Koswoski e Calisto (2015), uma das patologias mais significativas nas construções devido à instabilidade do solo é o recalque diferencial. Recalque é o termo utilizado na Engenharia Civil para caracterizar o fenômeno que ocorre quando uma edificação sofre um rebaixamento devido ao adensamento do solo sob sua fundação.

Dessa forma, este trabalho tem como objetivo expor e discutir alguns casos de construções que desenvolveram patologias na sua estrutura, por terem sido construídas em terrenos de lixões e/ou aterros desativados.

\section{REFERENCIAL TEORICO}

Com a determinação do encerramento dos lixões nos últimos anos em cumprimento a Política Nacional de Resíduos sólidos (PNRS), Lei ${ }^{\circ}$ 12.305/10, muitos terrenos que antes eram locais de deposição de lixo, têm se tornado solo de fundação de construções. De acordo com Marinho (2010), construções em antigos aterros ou lixões não deveriam ser feitas, isto porque o terreno torna-se uma massa desuniforme e com muitos vazios, assemelhando-se a uma esponja, tendo como consequência alteração na sua resistência.

A construção em locais onde haviam lixões, principalmente aqueles com altos índices de matéria orgânica, é umtema de estudo na área da Engenharia Civil, principalmente quando realacionamos isso aos problemas estruturais decorrentes de recalques diferenciais em fundações superficiais. Tais problemas surgem porque a matéria orgânica em contato com o solo modifica suas características físicas e químicas provocando perda de resistência e aumento da sua compressibilidade.

De acordo com reportagens realizadas pela Folha de São Paulo (2010) e G1 (2011), residências construídas sobre o lixão nos municípios de Franca - SP e Mauá - SP, apresentaram manifestações patológicas do tipo recalque diferencial, colocando em risco os moradores. Conforme relatou o representante da gestão municipal, mesmo depois de uma década de encerramento do lixão, a influência da matéria orgânica no solo não foi superada, pois uma analise do solo expedida pelo órgão judiciário mostrou instabilidade no solo, e à profundidade de $5 \mathrm{~m}$ verificaram-se camadas formadas por resíduos industriais e domésticos.

Qualquer tipo de solo submetido a um carregamento, sofre recalques, podendo ser em maior ou menor grau, a depender das propriedades das camadas constituintes e da intensidade do carregamento. Os recalques geralmente tendem a cessar ou estabilizar após certo período de tempo, prolongado ou não, e que depende das características geotécnicas dos solos (MILITITSKY, 2005; KOSWOSKI e CALISTO, 2015).

O recalque é a principal causa de trincas, fissuras e rachaduras em edificações, principalmente quando ocorre o recalque diferencial, ou seja, uma parte da obra rebaixa mais que a outra gerando esforços estruturais não previstos e podendo até levar a obra a ruína, que é comum em fundações sobre solos compressíveis, objeto de estudo deste trabalho.

\subsection{Solo na Construção Civil}

Solo é definido como o aglomerado de partículas minerais dispersas ou fracamente ligadas, decorrente da decomposição de rochas, sendo ocasionado por processos físicos ou químicos, conhecido como intemperismo (CRAIG \& KNAPPETT, 2016).

Para Caputo (1989), o solo é um material formado por um conjunto de partículas que apresentam vazios entre si, podendo ser preenchidos parcial ou totalmente de água. O solo se apresenta geralmente como um sistema aleatório formado por três fases: fase sólida, fase liquida e fase gasosa. 
O solo é o material mais antigo e comum empregado na construção, sendo uma matéria prima muito heterogênea cujo o comportamento é extremamente complexo, dificultando a elaboração de um modelo exato que possa caracterizar suas propriedades e seu comportamento (SOUSA, 2015).

\subsection{Solos orgânicos e suas características}

Segundo Pinto (2006), solos orgânicos são aqueles que possuem uma quantidade considerável de matéria em decomposição, de origem vegetal ou animal em diversas fases de decomposição, sendo de fácil identificação pela sua cor escura e odor forte característico.

O material orgânico do solo pode possuir ainda fragmentos de carvão finamente divididos, substâncias húmicas, biomassa meso e microbiana, e ainda outros compostos orgânicos naturalmente presentes no solo, podendo estar ou não associados a materiais minerais em diversas proporções (SANTOS et al., 2018).

Conforme Santos et al. (2018), as propriedades dos componentes orgânicos do solo devem predominar em relação as propriedades dos componentes inorgânicos. Assim, o solo deve apresentar um teor de carbono mínimo de $80 \mathrm{~g} / \mathrm{kg}$, segundo o método analítico escolhido pelo Centro Nacional de Pesquisa de Solos da Empresa Brasileira de Pesquisa Agropecuária (Embrapa - Solos).

Para Pinto (2006), solos orgânicos em geral apresentam um percentual de massa entre 4 e $20 \%$ de matéria orgânica em sua composição, ou seja, em uma amostra de solo de $1 \mathrm{~kg}$, a matéria orgânica presente pode chegar a $0,2 \mathrm{~kg}$.

Além disso, é classificado como solo orgânico aquele que apresenta o valor do Limite de Liquidez de uma amostra seca em estufa $75 \%$ menor que seu Limite de Liquidez em estado natural, sem ter passado pelo processo de secagem em estufa. Os solos orgânicos são encontrados geralmente em depósitos litorâneos, cujas camadas possuem de 3 a 10 metros de profundidade, podendo se deparar com esses solos em córregos e várzeas de rios (PINTO, 2006).

Os solos orgânicos tambem são formados por filamentos de pequenas dimensões e, possuem um comportamento altamente compressível. De acordo com o Sistema de Classificação Unificada, estes, são denominados de Turfas (CAPUTO, 1989).

Devido a sua extrema compressibilidade, os solos orgânicos são problemáticos para a construção civil, dificultando assim sua utilização como camada de apoio em fundações. Em geral, esses solos apresentam um índice de vazios maior que os demais solos, pelo fato de serem constituídos de sedimentos jovens, o que ocasiona uma baixa capacidade de suporte de carga para fundações (PINTO, 2006).

\subsection{Tipos de fundações}

\subsubsection{Fundaçoes rasas}

Segundo a NBR 6122 (Projeto e execução de fundações), fundações rasas são definidas como elementos de fundação cuja a carga é distribuída predominantemente pela base da fundação. Além disso, as fundações rasas possuem a profundidade de assentamento em relação ao terreno inferior a duas vezes a menor dimensão da fundação. Segundo a norma, as fundações superficiais são: as sapatas, os blocos, os radiers, as sapatas associadas, as vigas de fundação e as sapatas corridas (ABNT, 1996).

- Sapata: é um elemento de fundação executado em concreto armado, em que as tensões de tração atuantes são resistidas pela armadura empregada. Pode possuir diversas formas geométricas, como retangular, trapezoidal e, a mais comum quadrada (ABNT, 1996).

- Blocos: são elementos de fundação construídos em concreto simples, dimensionado para que as tensões de tração solicitantes sejam resistidas pelo concreto. Apresentam geralmente formato retangular ou quadrangular (ABNT, 1996).

- Radier: fundação superficial que cobre toda a projeção da edificação, abrangendo assim todos os pilares, bem como os carregamentos distribuídos (ABNT, 1996).

- Sapata associada (ou radier parcial): é um tipo de sapata que abrange alguns pilares, sendo que, os centros não correspondem ao mesmo alinhamento em planta (ABNT, 1996).

- Viga de fundação: fundação superficial que abrange vários pilares que possuem centros locados no mesmo alinhamento (ABNT, 1996).

- Sapata corrida: fundação que suporta uma carga distribuída atuando linearmente (ABNT, 1996).

\subsubsection{Fundações profundas}

De acordo com a norma NBR 6122, as fundações profundas são elementos de fundação que transmitem a carga pela sua base, bem como pela sua lateral ou por combinação das duas. Além disso, fundações profundas são assentadas a 
uma profundidade maior que o dobro da sua dimensão inferior e, obrigatoriamente a uma profundidade mínima de $3 \mathrm{~m}$. A fundações profundas podem ser: estacas, os tubulões e os caixões (ABNT, 1996).

- Estacas: fundações em que a execução é realizada por equipamentos, sem que haja a descida de operário na escavação em nenhuma de suas etapas. Existem diversos tipos de estacas, como as estacas de madeira, aço, concreto prémoldado, concreto moldado in situ ou mistas. Existem ainda outros tipos de estacas, como estaca cravada por percussão, estaca cravada por prensagem, estaca escavada, com injeção, estaca tipo broca, estaca apiloada, estaca tipo strauss, estaca escavada, estaca tipo franki, estaca mista e estaca "hélice contínua".ou mistos (ABNT, 1996).

- Tubulões: fundações de formato cilíndrico, onde há a necessidade da descida de operário em sua etapa final para realizar a escavação, podendo ser executada a céu aberto ou a ar comprimido e, ainda, ter ou não base alargada (ABNT, 1996).

- Caixões: possuem formato prismático, onde é realizada a escavação interna e a concretagem na superfície, existindo a possibilidade de ser usado ar comprimido e podendo possuir base alargada (ABNT, 1996).

\subsection{Patologia nas Fundações}

De acordo com França, et al (2011) o termo patologia deriva de duas palavras gregas páthos $=$ doença e lógos $=$ estudo, é amplamente utilizada na ciência e sua denominação varia de acordo com o ramo da atividade a que se refere. $\mathrm{Na}$ engenharia civil passou-se a usar este termo ao se referir dos problemas que as estruturas apresentam.

O estudo sobre a Patologia é tão importante e merecedora de atenção quanto ao estudo das fundações e estruturas, pois esse problema pode causar prejuízos não apenas financeiros, mas, dependendo do tipo do problema patológico, este pode causar a ruína das edificações e consequentemente perdas humanas, que são irreparáveis.

Santos (2018) diz que, quando uma edificação apresenta algum problema em sua integridade, podem surgir sinais externos, sintomas, indicando que algo não está correto. Koswoski e Calisto (2015) relaciona a causa mais frequente de problemas de fundações com a ausência ou incompleta investigação do subsolo, corroborando em $80 \%$ para casos de mau desempenho de fundações de obras pequenas e médias.

Para Sabbatini (1986), problemas com as fundações podem ser devido a compactação ineficiente, uso de materiais inadequados, deformação do solo abaixo do aterro natural sobre aterros e desconhecimento dos mecanismos envolvidos. Para fundações em solo que outrora tenha sido local de lixão ou aterro, a situação é ainda mais delicada devido ao acréscimo das tensões que provoca recalque pela decomposição dos resíduos ao longo do tempo.

Os danos causados por recalques podem ser divididos em três grupos: visuais e estéticos (sem riscos de qualquer natureza), danos comprometendo o uso e funcionalidade do prédio e danos estruturais pondo em risco a segurança dos usuários (MILITITSKY, 2005). Uma das principais manifestações patológicas referente ao recalque diferencial é a apresentação de fissuras inclinadas como mostra a Figura 1, além disso, há uma variação na abertura da fissura quando o recalque é acentuado (KOSWOSKI e CALISTO, 2015)
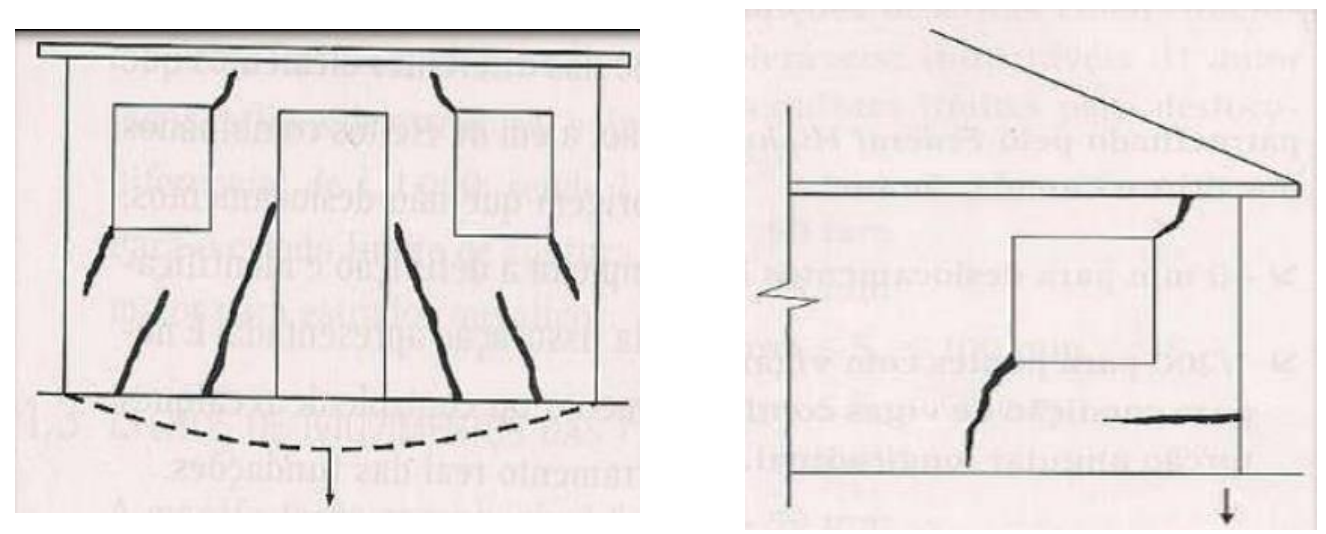

Figura 1: Exemplo de recalque diferencial - Fissuras

Fonte: Adaptado de Koswoski e Calisto (2015)

\section{METODOLOGIA}

Silveira e Córdova (2009), refere-se à pesquisa como sendo a inquisição, o procedimento sistemático e intensivo, que tem por objetivo descobrir e interpretar os fatos que estão inseridos em uma determinada realidade. Dessa forma, este trabalho se trata de uma pesquisa qualitativa pois este não necessita de métodos numericos e técnicas estatísticas. Na 
análise qualitativa não existe a necessidade de priorizar a quantificação de valores, a pesquisa neste caso preocupa-se essencialmente mais com o processo do que o produto (PRODANOV \& FREITAS, 2013).

Na pesquisa qualitativa, o conhecimento do pesquisador é parcial e limitado. O objetivo da amostra é de produzir informações aprofundadas e ilustrativas: seja ela pequena ou grande, o que importa é que ela seja capaz de produzir novas informações (Silveira e Córdova, 2009 apud DESLAURIERS, 1991, p. 58).

Segundo Praça (2015), a pesquisa em questão possui cunho exclusivamente teórica, sendo esta baseada em análises de referências que são embasadas por outros autores teóricos, não existindo analises experimentais.

Este trabalho tambem se classifica como uma pesquisa bibliográfica, na qual se baseia na revisão técnica de trabalhos já publicados como livros, revistas, artigos científicos, jornais, fotos, documentos, teses, normas, internet, entre outros.

Em resumo, este trabalho consistiu em algumas etapas: Em primeiro lugar foi delimitado o objeto de estudo, que foi discutir os problemas causados nas edificações em solo orgânico; em seguida, realizou-se o levantamento bibliográfico relacionado ao tema; e por último foi realizada as análises das bibliografias utilizadas no trabalho.

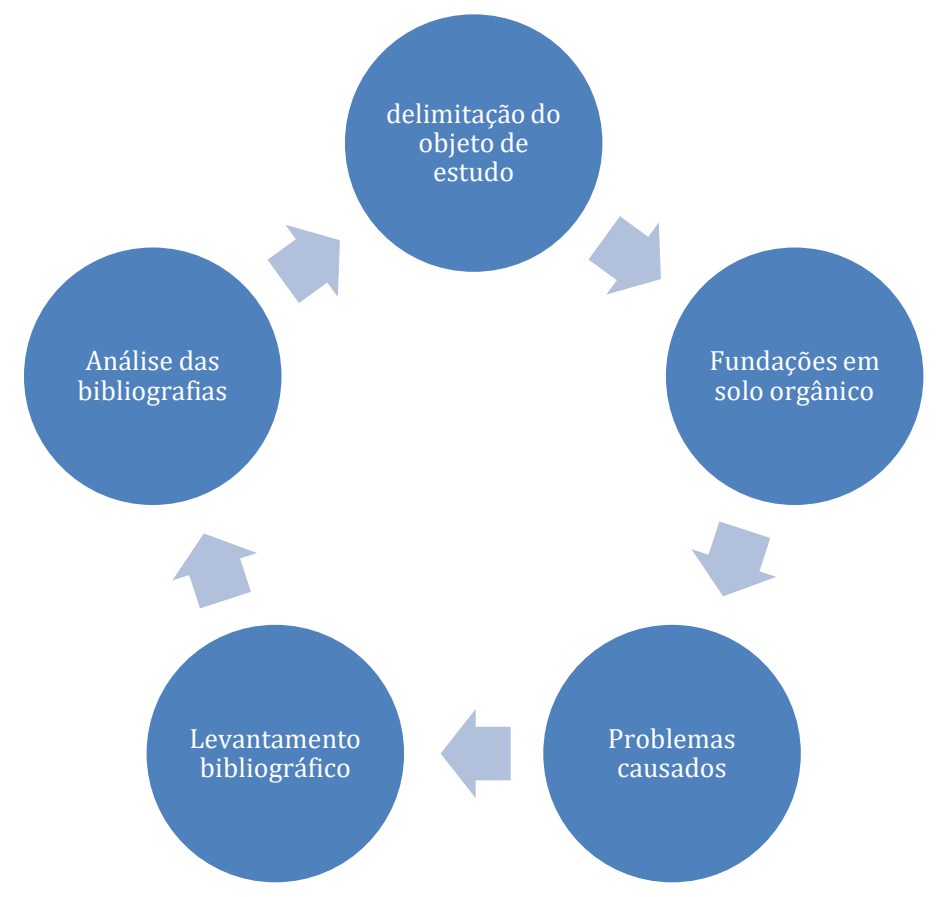

\section{RESULTADOS E DISCUSSÕES}

Após o encerramento dos aterros comuns, a decomposição dos resíduos continua ativa provocando alteração no solo, tornando-o compressível. De acordo com Aquino (2018) em área com predominância de resíduos sólidos, as fundações dos imóveis são desestabilizadas, isto é, há acomodação de terra em consequência da decomposição dos resíduos. Para Marinho (2010) em solo que já abrigou lixões e/ou aterros não deveria ser usado para construções, pois o solo torna-se compressível, ou seja, muito deformável.

Embora essa seja a recomendação, a falta de condições socioeconômicas torna os lixões destivados locais atraentes para povoamento de classe mais vulnerável socioeconomicamente. Acrescentando a este fator tem-se a falta de monitoramento da área pelos órgãos públicos o que torna as condições ainda mais irregulares e preocupantes (COSTA; NISHIYAMA, 2012; AQUINO, 2018)

Diante disso, matérias jornalísticas e trabalhos acadêmicos tem revelado situações reais do que ocorre com obras construídas em terrenos de antigos lixões. Embora vários casos tenham sido relatados, este trabalho discutirá duas situações, uma ocorrida na zona urbana do município de Pereiro no estado do Ceará e a outra em um conjunto habitacional em Ribeirão Preto, no estado de São Paulo.

De acordo com alguns registros fotográficos e levantamento sobre o histórico da área pelos moradores, foi identificado que o terreno outrora foi local de lixão do município cearense, tendo sido desativado a mais de 10 anos.

Conforme Aquino (2018), os entrevistados informaram que os resíduos eram queimados e os locais recebiam a cobertura de terra, e a partir daí eram desmembrados os loteamentos. As Figuras 2 (a,b,c) mostram algumas das patologias, do tipo fissura, que provavelmente pode ter sido resultante de um recalque diferencial devido a compressibilidade do solo. 

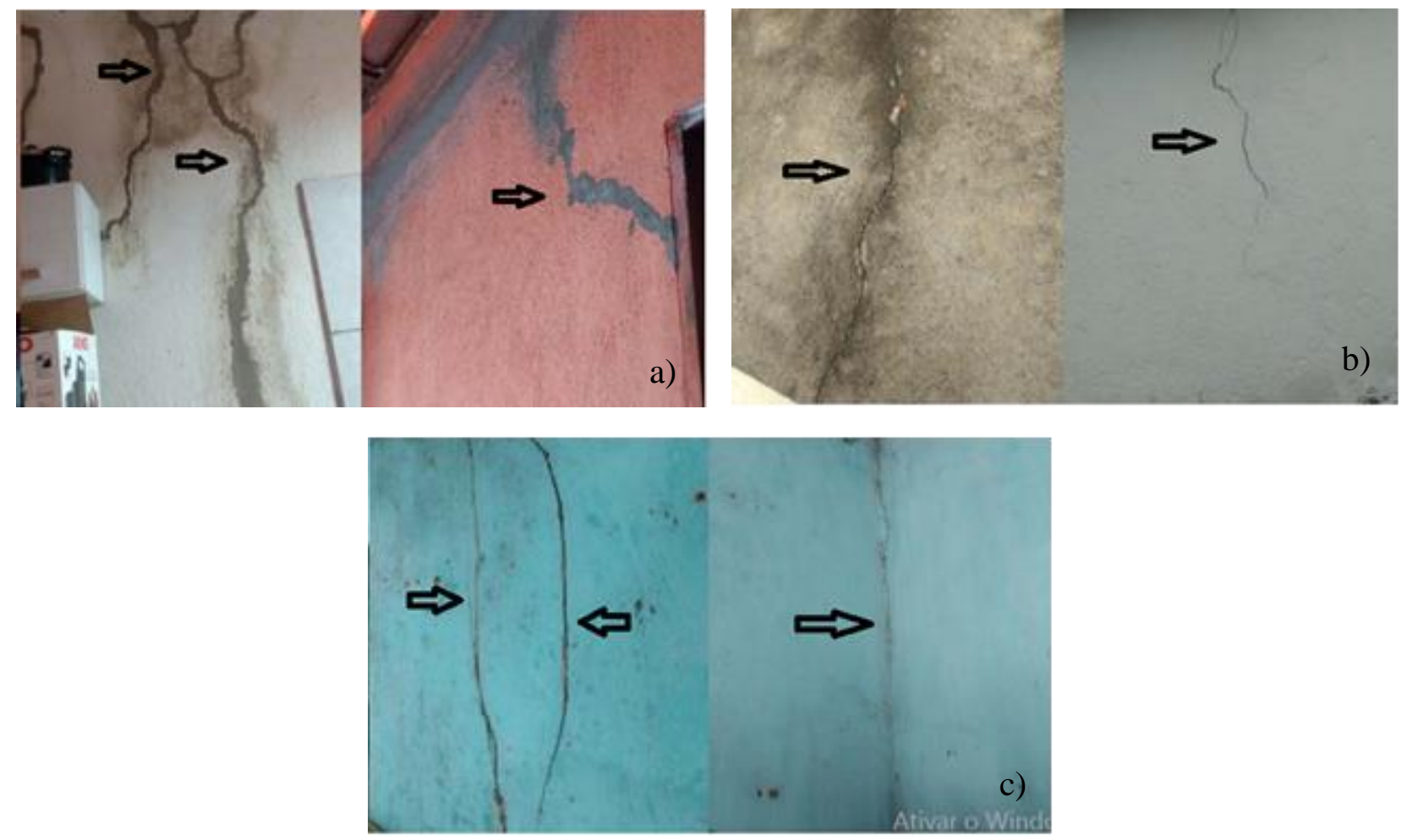

Figura 2: Fissuras na alvenaria interior e exterior de residências unifamiliares (a,b e c da esquerda para a direita de cima para baixo).

Fonte: Adaptado de Aquino (2018).

Embora não se tenha feito um estudo mais aprofundado do local, sendo apenas superficial, mas mediante os conceitos abordados pela literatura sobre problemas estruturais nas fundações em solos orgânicos, pode-se deduzir através dos relatos obtidos pelos entrevistados e as imagens que, os danos possivelmente sejam decorrentes de recalque diferencial devido a característica de solo compressível que é o solo modificado pela ação de material orgânico.

Uma fissura pode revelar manifestações patológicas distintas, sendo necessário conhecer as características de cada uma delas antes de tomar qualquer iniciativa para contê-las. De acordo com Thomaz e Carneiro (2013), a variação da temperatura junto a fundação faz com que ocorra o resfriamento rápido e retração do concreto, a fundação acaba impedindo o encurtamento do concreto provocando fissuração. Em caso de efeito de sobrecarga, como o próprio nome diz é causada por deformação devido ao excesso de cargas na estrutura os quais não foram consideradas no dimensionamento. Um dos motivos de fissuração em vigas é o grande vão que muitas vezes o modelo arquitetônico impõe, contribuindo para um aumento nas flechas ao longo do tempo.

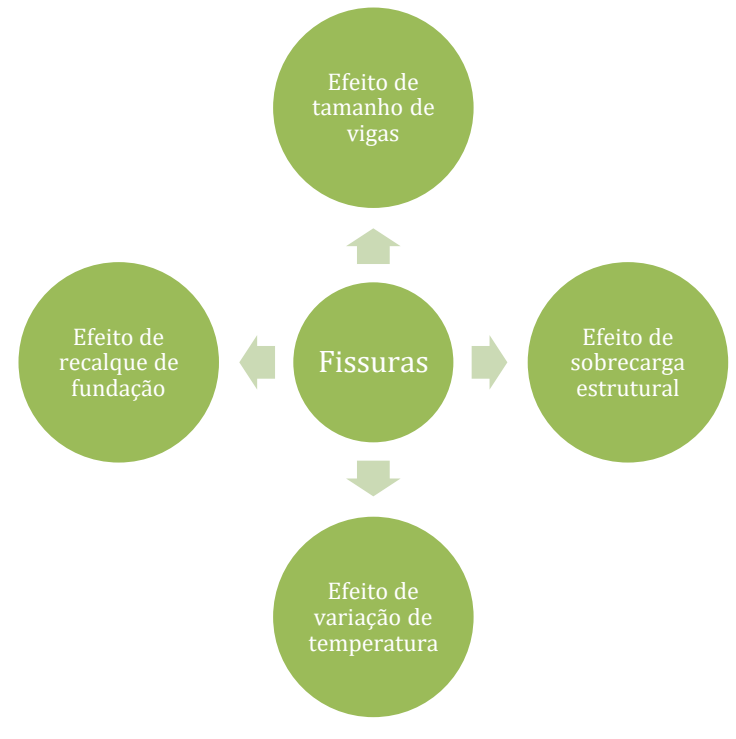


O outro caso a ser discutido é um conjunto habitacional localizado na cidade de Ribeirão Preto, SP. De acordo com Bervique (2008), os moradores da localidade relataram problemas estruturais nas residências sendo convocados a saírem de suas residências. Um dos moradores relatou que uma investigação no subsolo realizada por um geólogo constatou que havia resíduos sólidos em decomposição a 1 metro de profundidade. As Figuras 3 e 4 mostram os problemas na alvenaria de algumas residências.
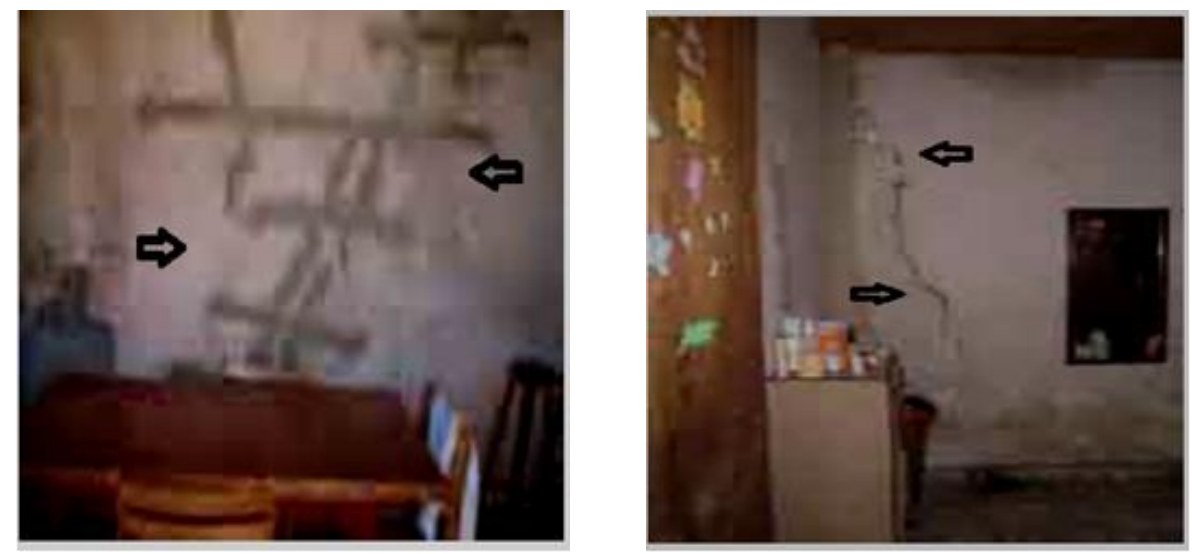

Figura 3, 4: Trincas comprometedoras à estrutura

Fonte: Adaptado de Bervique, (2008)

De acordo com o que foi discutido, verifica-se que as fissuras são em maioria na diagonal, próximo as portas e janelas e pilar o que representa um recalque diferencial. E isso tem ocorrido em consequência da compactação inadequada dos resíduos sólidos depositados provocando os problemas estruturais apresentados pelas unidades habitacionais, decorrentes da fragilização do terreno e acomodação do solo.

\section{CONCLUSÃO}

Um dos grandes problemas da sociedade moderna é o consumo e a grande produção de resíduos sólidos. Infelizmente, na maioria dos casos, esses resíduos não são armazenados em um aterro sanitário, sendo lançados em locais impróprios ocasionando mudanças químicas, físicas e biológicas no solo.

Diante do exposto, são perceptíveis os problemas gerados devido à construção em terrenos de lixões desativados, onde predominam os solos orgânicos de baixa resistência mecânica e alta compressibilidade. Esses problemas são recorrentes em solos com grandes quantidades de matéria orgânica proveniente de lixões. Devido a essa condição, o solo perde bastante resistência para suportar as cargas oriundas das edificações, que consequentemente apresentam várias patologias nas fundações como recalques que acabam danificando e comprometendo as estruturas, seja esteticamente como também estruturalmente, a exemplo de fissuras e trincas, podendo em casos extremos levar à ruina das edificações.

\section{REFERÊNCIAS}

AQUINO, Yara Caroline de. Abordagem integrada para avaliação das áreas de aterros comuns em Pereiro/CE. 2018. 87 f. Trabalho de Conclusão de Curso (Graduação) - Universidade Federal Rural do Semi-Árido, Pau dos Ferros, 2018.

ASSOCIAÇÃO BRASILEIRA DE NORMAS TÉCNICAS. NBR 6122. Projeto e execução de fundações. Rio de Janeiro. 1996.

BERVIQUE, Jeannette Marcean. Estudo dos impactos ambientais causados pelo antigo lixão, no Jardim Juliana A e Jardim das Palmeiras II. 2008. 132 f. Trabalho de Conclusão de Curso (Mestrado em Tecnologia Ambienta) Universidade de Ribeirão Preto Centro de Ciências Exatas, Naturais e Tecnológicas, Ribeirão Preto, 2008.

CAPUTO, Homero Pinto. Mecânica dos solos e suas aplicações. São Paulo: Livros Técnicos e Científicos Editora Ltda, $6^{\text {a }}$ edição, v. 1, 1989.

CONSOLI, N. C.; Milititsky, J.; Schinaid, F. Patologias das Fundações. 1ª. ed. São Paulo: Editora Oficina de Textos, 2005. 191p.

COSTA, Rildo Aparecido; NISHIYAMA, Luiz. Zoneamento ambiental das áreas urbana e de expansão urbana de Caldas Novas (GO): uma contribuição metodológica. RAEGA - O Espaço Geográfico em Análise, [s.1.], v. 25, p.343372, 6 jul. 2012 


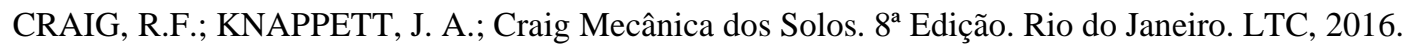

FRANÇA, et al. Patologia das construções: uma especialidade da engenharia civil. Revista Téchne. 2011.

KOSWOSKI. R; Calisto A. Efeito do recalque diferencial de fundações em estruturas de concreto armado e alvenaria de vedação. estudo de caso. U.T.F.P. Trabalho de conclusão de curso. 2015. 35 f.: il.

SILVEIRA e GERHART. Métodos de pesquisa. Coordenado pela Universidade Aberta do Brasil - UAB/UFRGS e pelo Curso de Graduação Tecnológica - Planejamento e Gestão para o Desenvolvimento Rural da SEAD/UFRGS. - Porto Alegre: Editora da UFRGS, 2009.

PRODANOV, Cleber Cristiano; FREITAS, Ernani Cesar de. Metodologia do trabalho cientifico: Métodos e técnicas da pesquisa e do trabalho acadêmico. UNIVERSIDADE FEEVALE. $2^{\circ}$ Edição. Novo Hamburgo - RS, 2013.

PINTO, Carlos de Souza. Curso Básico de Mecânica dos Solos em 16 Aulas/3a Edição. São Paulo: Oficina de Textos, 2006.

PRAÇA, Fabíola Silva Garcia. Metodologia da pesquisa científica: organização estrutural e os desafios para redigir o trabalho de conclusão. Revista Eletrônica "Diálogos Acadêmicos". nº 1, p. 72-87, JAN-JUL, 2015.

SANTOS, H. G. dos; JACOMINE, P. K. T.; ANJOS, L. H. C. dos; OLIVEIRA, V. A. de; LUMBRERAS, J. F.; COELHO, M. R.; ALMEIDA, J. A. de; ARAUJO FILHO, J. C. de; OLIVEIRA, J. B. de; CUNHA, T. J. F. Sistema Brasileiro de Classificação de Solos. 5. ed. rev. e ampl. Brasília, DF. Embrapa, 2018. 356 p. il. color.

SOUSA, Jéssica Siqueira de. Mecânica dos solos. Brasília. NT Editora, 2015. 188p.

SANTOS, et al. Estudo e Análise das Patologias da Ponte de Porto Nacional - TO. (2017). Revista Engenharia Estudo e Pesquise. ABPE. V. 17. N $\mathrm{N}^{\mathrm{O}}$ 2. Pg $31-41 . \quad \mathrm{Jul} / \mathrm{Dez} 2017 . \quad$ Disponível em: $>$ http://www.revistaeep.com/imagens/volume17_02/cap03.pdf<. Acesso em 05.07.2019.

SABBATINI, F. H.. Argamassas de assentamento para paredes de alvenaria estrutural. Boletim Técnico 02/86. EPUSP. São Paulo, 1986. 